\title{
ANÁLISE ESTRATÉGICA DO MANEJO FLORESTAL NA AMAZÔNIA BRASILEIRA
}

\author{
Humberto Angelo ${ }^{1}$, Julio Cesar da Silva ${ }^{2}$, Alexandre Nascimento de Almeida ${ }^{3}$, \\ Raquel de Souza Pompermayer ${ }^{4}$ \\ Eng. Florestal, Dr., Depto. de Engenharia Florestal, UnB, Brasília, DF, Brasil - humb@unb.br \\ Eng. Florestal, Dr., IBAMA, Brasília, DF, Brasil - lasjcs@bol.com.br \\ Eng. Florestal, Dr., Faculdade UnB de Planaltina, FUP, Planaltina, DF, Brasil - alexalmeida @unb.br \\ Eng $^{\mathrm{a}}$. Produção, Dr ${ }^{\mathrm{a}}$., UFVJM, Diamantina, MG, Brasil - rasop97@yahoo.com \\ Recebido para publicação: 21/10/2013 - Aceito para publicação: 30/01/2014
}

\begin{abstract}
Resumo
Este estudo trata da análise estratégica da produção madeireira sustentada na Amazônia brasileira com foco nos planos de manejo florestal da região. A metodologia empregada se baseou na utilização da análise SWOT para determinar os pontos fortes e fracos e as oportunidades e ameaças do manejo florestal na Amazônia. Para tanto, foram entrevistados 40 profissionais que trabalham com o manejo florestal na região. O principal ponto forte esteve relacionado ao manejo, servindo como forma de manutenção da cobertura florestal; o principal ponto fraco tem relação com a pouca fiscalização sobre a extração ilegal de madeira; a principal oportunidade refere-se à grande quantidade de áreas disponíveis para o manejo florestal; e a principal ameaça é a competição desleal com a madeira de origem legal.

Palavras-chave: Economia florestal; SWOT; floresta tropical.
\end{abstract}

\begin{abstract}
Strategic analysis of forest management in the Brazilian Amazon. This research develops a strategic analysis of supported timber production in the Brazilian Amazonia, with focus in the sustainable forest management plans in the region. The methodology is based on the use of SWOT Analysis to determine the strengths and weaknesses, opportunities and threats of forest in the Amazon. Therefore, we interviewed 40 professionals who work with forest management. As result, we identified as the main positive point the management as way of maintenance of the forest covering. On the other hand, the main weake point is the lack of control of illegal wooden extraction. The main opportunity is the great amount of available areas for the forest management. Finally, the main threat is the unfair competition with the illegal wood.

Keywords: Forest Economy; SWOT; rainforest.
\end{abstract}

\section{INTRODUÇÃO}

As práticas atuais de extração madeireira na Amazônia provocam uma ocupação desordenada, além de gerarem modelos de desenvolvimento que não levam em conta o uso dos recursos florestais mediante os planos de manejo florestal e em desrespeito às leis ambientais do Brasil. As principais causas do aparecimento desses modelos predatórios são a falta de uma política florestal coerente, que incentive o manejo das florestas em bases sustentáveis, e a falta de um zoneamento ecológico-econômico de acordo com as condições de cada região, problemas comumente encontrados em todos os países que possuem floresta tropical (DA SILVA, 2008).

O plano de manejo florestal para retirada da madeira é uma boa alternativa considerando o planejamento e o uso de técnicas adequadas, que garantam a continuidade da produção e reduzam o desperdício de madeira, além de certificar os produtos florestais com consequente valorização perante o mercado mundial.

Observando todas as potencialidades do manejo da floresta sob o ponto de vista socioeconômico, é possível identificar essa atividade como sendo uma boa oportunidade de gerar emprego e renda às 
comunidades que sobrevivem direta ou indiretamente da floresta. Sob o ponto de vista ambiental, é mais uma garantia da perpetuidade dos recursos florestais (MATSUNAGA, 2005).

As comunidades que vivem da floresta nem sempre usufruem do progresso e de melhorias nos seus índices de desenvolvimento humano, apesar do aumento da extração e do comércio de madeira, bem como da quantidade de produtos madeireiros industrializados. Essa realidade contraditória é verificada pelas ameaças enfrentadas pelo manejo florestal, que vão desde a falta de políticas para uso de terras públicas até a falta de estímulos econômicos e de créditos ao manejo (DA SILVA, 2008).

O manejo da floresta visando à extração de madeira possui algumas limitações, destacando-se, particularmente, a retirada ilegal do recurso madeireiro, competindo com a colheita de madeira orientada por meio de plano de manejo florestal sustentável (ANGELO et al., 2004). A madeira retirada da floresta de maneira ilegal possui preços muito reduzidos no mercado, se comparados com a madeira retirada de planos de manejo, inviabilizando os investimentos em manejo, em que o custo da madeira é significativamente maior.

O presente trabalho tem como objetivo a análise estratégica da produção madeireira sustentada na Amazônia brasileira. Para isso, propõe-se um ordenamento preferencial dos principais pontos fortes e fracos, oportunidades e ameaças ao manejo florestal sustentável na Amazônia, possibilitando a elaboração de políticas públicas direcionadas ao desenvolvimento sustentável da região.

\section{MATERIAL E MÉTODOS}

Foi utilizado um questionário de avaliação para a obtenção das opiniões de técnicos da área de manejo florestal, com relação às principais questões que refletem os pontos fortes e fracos, as oportunidades e as ameaças ao manejo florestal na Amazônia.

O questionário foi confeccionado em uma escala de importância de 10 pontos, atribuindo-se valor 1 para a questão menos importante e valor 10 para a questão de maior importância. A coleta de dados foi entre o período de maio e setembro de 2007 e a amostragem foi composta de 40 especialistas em manejo florestal. Aplicaram-se entrevistas com técnicos que trabalham com manejo florestal, representando os setores público (órgãos ambientais), privado (empresas florestais), acadêmico (universidades) e o chamado terceiro setor (ONGs).

A identificação do grau de importância das variáveis correspondentes às forças, fraquezas, oportunidades e ameaças foi a partir da soma de todas as notas dadas para cada questão considerada. Com vistas a se obterem os valores percentuais, realizou-se uma análise de frequência simples para identificar os itens com maior pontuação e sua relação com a nota total, possibilitando avaliar o grau de importância das variáveis em termos percentuais.

Da mesma forma que Nasri (2011), o instrumental analítico seguiu a técnica da análise de Forças, Fraquezas, Oportunidades e Ameaças (SWOT), permitindo ao pesquisador identificar e avaliar as forças e fraquezas de um empreendimento, bem como identificar as oportunidades e as ameaças a que ele está sujeito (Figura 1).

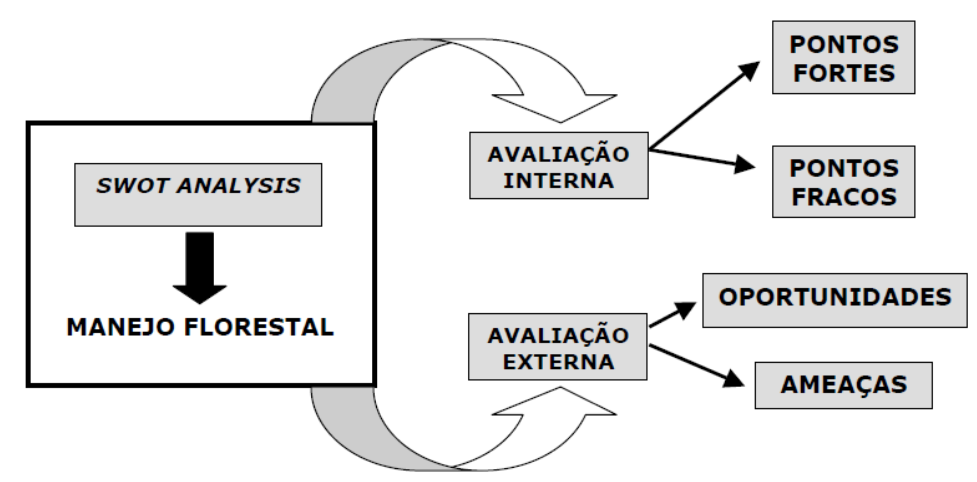

Figura 1. Esquema do método da análise SWOT aplicado ao manejo florestal.

Figure 1. Outline of the SWOT analysis applied to forest management. 
Os pontos fortes e fracos são determinados pela posição atual do manejo florestal e se relacionam, quase sempre, a fatores internos. Já as oportunidades e ameaças são antecipações do futuro e estão relacionadas a fatores externos. $\mathrm{O}$ ambiente interno pode ser controlado pelos atores ligados ao manejo florestal, uma vez que ele é resultado das estratégias de atuação definidas pelos próprios manejadores. Assim, durante a análise, quando percebido um ponto forte, ele deve ser ressaltado ao máximo, e quando for percebido um ponto fraco, deve-se agir para controlá-lo ou pelo menos minimizar seus efeitos. Por outro lado, o ambiente externo está totalmente fora de controle, mas, apesar de não poder controlá-lo, o manejador deve conhecê-lo e monitorá-lo com frequência, de forma a aproveitar as oportunidades e evitar as ameaças.

Apesar da importância da análise SWOT no planejamento estratégico e tomada de decisão, a ferramenta possui os seguintes inconvenientes: depende de instintos subjetivos, evita quantificação, não tem poder de prognóstico e nem um suporte teórico concreto para sua validação como uma prática confiável (AGARWAL et al., 2012; COMAN; RONEN, 2009; HELMS; NIXON, 2010). Porém, segundo Ulrich (2002), dada a sua simplicidade, a análise SWOT é uma das técnicas mais utilizadas em investigação social, quer na elaboração de diagnósticos, quer em análise organizacional ou elaboração de planos.

\section{RESULTADOS E DISCUSSÃO}

\section{O ambiente interno: pontos fortes do manejo florestal}

A partir da análise das respostas dos entrevistados estabeleceu-se uma classificação dos pontos fortes do manejo florestal na Amazônia brasileira. Na figura 2 estão apresentadas, em ordem decrescente de importância, as avaliações dos dez pontos fortes do manejo florestal na Amazônia brasileira.

De modo geral, a questão referente ao "manejo como forma de manutenção da cobertura florestal" foi a mais bem avaliada em todos os segmentos analisados, representando $15 \%$ da ponderação total (2200 pontos) atribuída às dez questões avaliadas. Esse percentual aponta que, entre as questões avaliadas, a manutenção da cobertura florestal na Amazônia é o principal ponto forte do manejo, conforme a opinião dos entrevistados.

Em segunda e terceira posição estão os pontos fortes referentes ao "manejo com garantia de continuidade na produção de madeira" e o "manejo florestal como alternativa ao desmatamento", com cerca de $12,9 \%$ e $10,9 \%$ da ponderação total atribuída pelas dez questões avaliadas, respectivamente.

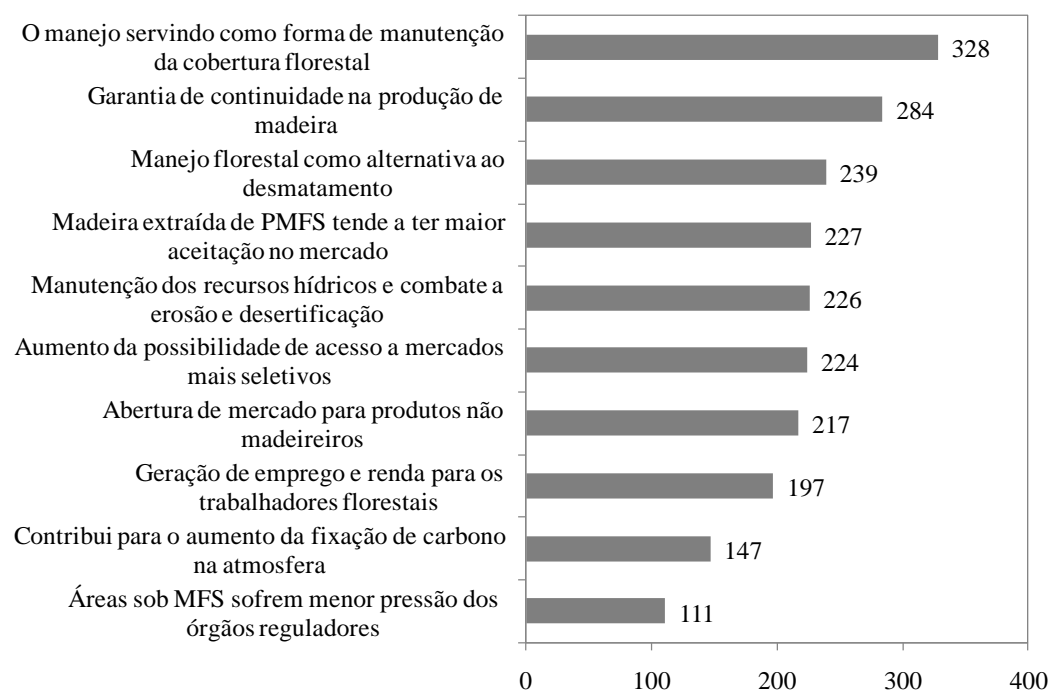

Figura 2. Pontos fortes do manejo florestal e pontuações segundo os grupos avaliados.

Figure 2. Strengths of forest management scores according to the evaluated groups.

Com o avanço crescente da fronteira agrícola e da indústria madeireira, a cobertura florestal poderá diminuir dos atuais 5,3 milhões de quilômetros quadrados, o que representa $85 \%$ da área original, 
para 3,2 milhões de quilômetros quadrados em 2050, o equivalente a 53\% da cobertura original (MARENGO, 2006). Esse fato reforça ainda mais a relevância do manejo florestal como alternativa ao desmatamento e à manutenção da cobertura florestal, além da possibilidade de geração de renda com a continuidade da produção madeireira, considerações essas que provavelmente influenciaram as ponderações estabelecidas pelos especialistas consultados.

Não obstante, os resultados apresentados na figura 2 constataram que "áreas sob MFS sofrem menor pressão dos órgãos reguladores" foi a questão de menor relevância para os segmentos avaliados, não ultrapassando o percentual de $5 \%$ da ponderação total atribuída aos dez pontos fortes avaliados. De modo geral, esse percentual indica que as "áreas sob MFS sofrem menor pressão dos órgãos reguladores", segundo o julgamento dos especialistas, não é ponto forte do manejo florestal. O fato é que existe a discordância de que os órgãos ambientais exerçam pouca pressão em áreas manejadas.

\section{Ambiente interno: pontos fracos do manejo florestal}

A figura 3 estabelece uma classificação em ordem decrescente de importância dos pontos fracos do manejo sustentável da Amazônia, de acordo com o "valor" atribuído pelos especialistas consultados. De modo geral, os resultados mostraram que alguns dos pontos fracos foram os mais valorizados pelos entrevistados, recebendo os maiores percentuais de respostas. É o caso das questões referentes ao "excesso de burocracia e regras pouco flexíveis", a "pouca fiscalização sobre a extração ilegal de madeira" e ao "alto custo de implantação e manutenção dos planos de manejo", que receberam, respectivamente, $12,2 \%, 12,0 \%$ e $11,2 \%$ do percentual total de respostas.

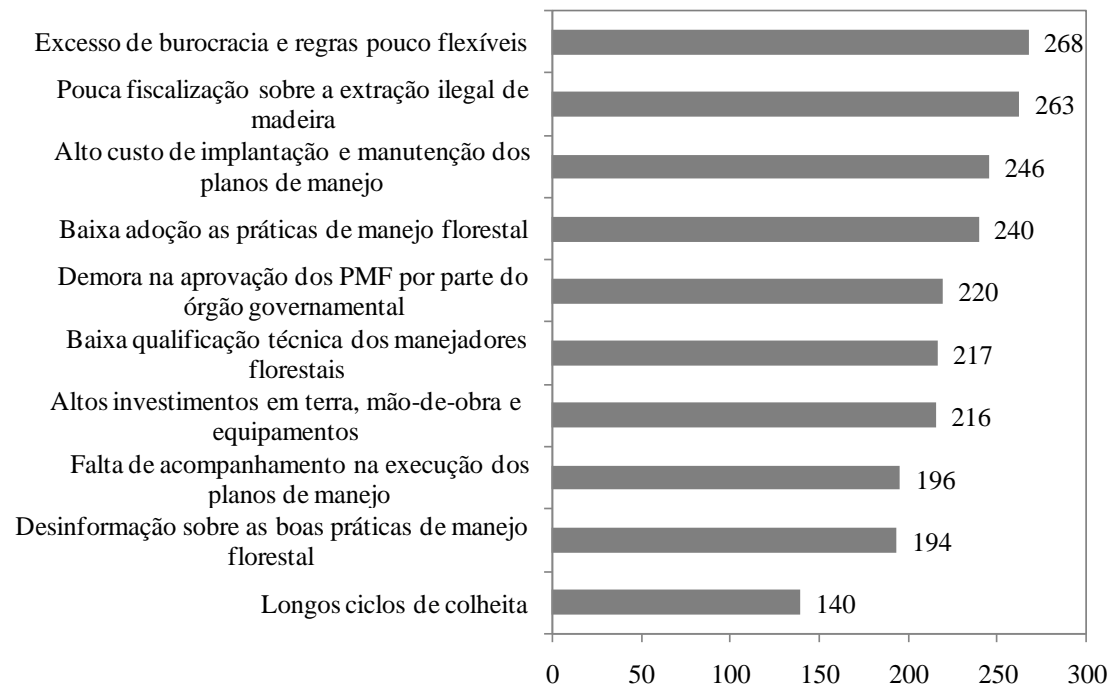

Figura 3. Pontos fracos do manejo florestal e pontuações segundo os grupos avaliados.

Figure 3. Weaknesses of forest management and scores according to the evaluated groups.

As evidências apontadas na literatura reforçam a percepção dos entrevistados para os pontos realmente mais fracos. São evidências que apontam, a "pouca fiscalização sobre a extração ilegal de madeira" e o "alto custo de implantação e manutenção dos planos de manejo", como principais entraves ao manejo florestal sustentável na Amazônia. Sabogal et al. (2000) constataram que o manejo é fortemente influenciado pela falta de fiscalização dos órgãos ambientais na retirada clandestina de madeira, que por sua vez concorre diretamente com a madeira manejada durante a comercialização.

A falta de instrumentos e mecanismos eficazes e de recursos humanos e financeiros inibem as ações do governo na fiscalização da imensa área da floresta amazônica, para impedir a retirada predatória da madeira, ou mesmo mitigar ações que degradam a floresta. Matsunaga (2005) estudou um plano de manejo na Amazônia, constatando que o custo total da madeira em tora colocada na serraria significa, aproximadamente, $60 \%$ do custo de todas as atividades inerentes à retirada da madeira. Outro fator que onera a cadeia produtiva é o custo de transporte entre a floresta e a serraria, que responde por $40 \%$ dos 
custos da atividade madeireira. $\mathrm{O}$ autor citado destacou, ainda, que o valor global do plano de manejo supera em $25 \%$ o valor da madeira comercializada no mercado local.

Por outro lado, os resultados obtidos na figura 3 mostraram que pouca importância foi atribuída à "desinformação sobre as boas práticas de manejo florestal" e à questão que trata de "longos ciclos de colheita", que receberam um percentual de respostas da ordem de $8,8 \%$ e $6,4 \%$ do percentual total. Os baixos percentuais sugerem que os especialistas consultados consideram essas questões de pouca relevância no contexto das limitações do manejo florestal.

Provavelmente, a minimização do problema referente ao longo ciclo de colheita necessário ao manejo na Amazônia deve-se ao grande estoque de floresta existente. O Canadá, referência em manejo florestal de florestas naturais, tal como o Brasil possui cerca de metade de seu território coberto por florestas naturais com ciclos de corte extremamente longos, porém isso não é um problema no suprimento de madeira do país, visto que a área colhida não chega a $0,4 \%$ das suas florestas comerciais, possibilitando que a floresta colhida se regenere tranquilamente e o país conte com uma indústria de base florestal importante e desenvolvida (REVISTA DA MADEIRA (REMADE), 2002).

Por outro lado, o excesso de burocracia e regras pouco flexíveis indicadas como principal ponto fraco ao manejo na Amazônia reflete a constante mudança de legislação, principalmente em relação às exigências técnicas na forma de instruções normativas e portarias. Em geral, as normas técnicas sobre manejo florestal são instáveis e com durabilidade média em torno de três anos.

\section{Ambiente externo: oportunidades do manejo florestal}

$\mathrm{Na}$ figura 4 estão sumarizados os resultados da avaliação das principais questões referentes às oportunidades do manejo florestal na Amazônia brasileira. A partir das ponderações atribuídas pelos especialistas, estabeleceu-se um ordenamento decrescente de preferência das questões avaliadas. Em todos os segmentos analisados, a "grande quantidade de áreas disponíveis para o manejo florestal", as "políticas de ordenamento florestal mais desenvolvido para a Amazônia" e os "bons preços da madeira nos mercados nacional e internacional" foram, entre as dez questões avaliadas, as que alcançaram os maiores percentuais de respostas, com, respectivamente, $11,5 \%, 10,7 \%$ e $10,6 \%$ do total de respostas (2200 pontos). Em contrapartida, constatou-se, entre as dez questões avaliadas, que a oportunidade de manejo menos atraente é o "mercado de crédito de carbono", atingindo um percentual de apenas 7,6\% do total de respostas, em todos os setores analisados.

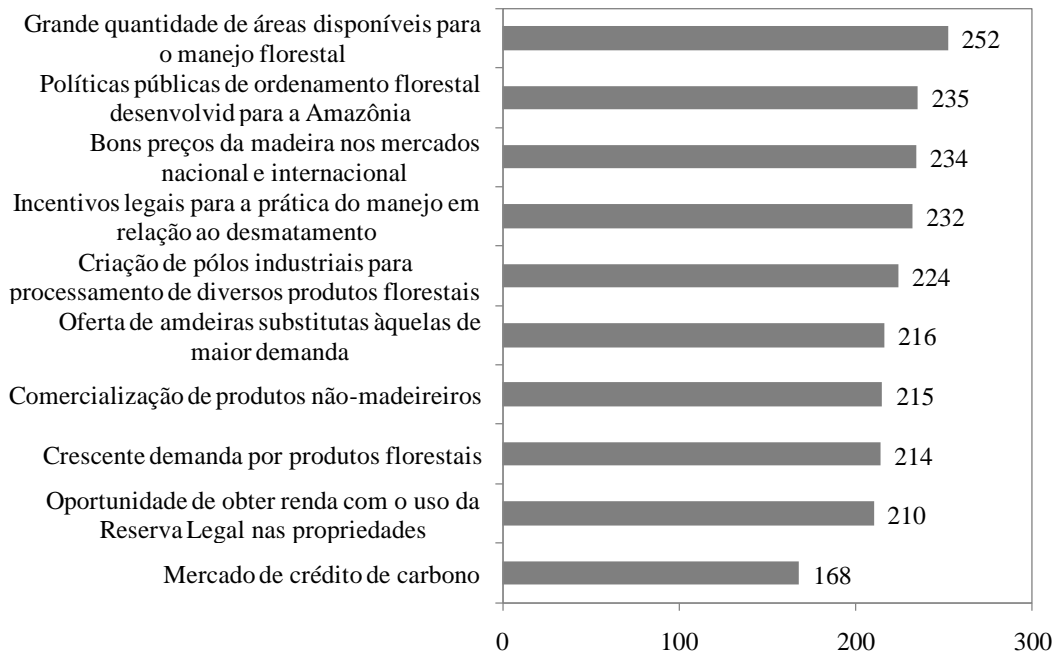

Figura 4. As oportunidades do manejo florestal e pontuações segundo os grupos avaliados.

Figure 4. The opportunities of forest management and scores according to the evaluated groups.

A grande relevância da primeira oportunidade de manejo em comparação com as demais pode ser explicada pelo valor expressivo da área disponível para manejo florestal na região, além da alta demanda por madeiras tropicais nos mercados interno e externo. Esses aspectos são atrativos para 
empresários ligados ao setor florestal, que buscam boas oportunidades de produção e comércio de madeiras e de outros produtos que a floresta pode oferecer.

O percentual de respostas verificado para a segunda oportunidade mais bem avaliada, "políticas de ordenamento florestal mais desenvolvido para a Amazônia", reflete a importância dessa questão para os entrevistados. Esse resultado mostra que há um consenso entre os especialistas entrevistados e as evidências teóricas encontradas por Homma (2005) e Freitas (2003).

Homma (2005) argumenta que toda política pública para essa região deve estar voltada, primeiramente, para a manutenção da floresta e, num segundo momento, para a utilização de áreas já desmatadas, as quais atingiram mais de 67 milhões de hectares em 2004.

Freitas (2003) ressalta que a recuperação de áreas desmatadas constitui-se numa importante alternativa política para a Amazônia, pois o desmatamento comprometeu margens de rios, áreas importantes para a flora e a fauna e sítios arqueológicos, sobretudo nas últimas quatro décadas. Nesse sentido, ações ambientais patrocinadas por organismos internacionais, visando à redução dos desmatamentos e à promoção de mudanças na forma de uso dos recursos florestais, constituem-se num importante instrumento de ordenamento florestal. Assim, ações do governo federal voltadas, por exemplo, à criação de novas áreas protegidas na Amazônia, como oportunidade ao manejo florestal sustentável, poderão proporcionar benefícios às comunidades que dependem da floresta.

A percepção não tão otimista ao mercado de crédito de carbono pode ter sido influenciada pela incerteza quanto à metodologia de projetos dessa natureza, preocupação essa compartilhada por Finco et $a l$. (2006). Segundo os autores, a metodologia inerente a projetos de sequestro de carbono não está ainda desenvolvida, existindo incertezas quanto ao real potencial dos projetos de mecanismo de desenvolvimento limpo (MDL), principalmente com relação aos projetos voltados ao aproveitamento das florestas.

\section{O ambiente externo: ameaças ao manejo florestal}

Com base nas opiniões dos entrevistados, estabeleceu-se um ordenamento preferencial das principais ameaças ao manejo florestal na Amazônia brasileira, conforme destacado na figura 5. De modo geral, os resultados mostraram que a "competição desleal com a madeira de origem ilegal" e a "exploração não manejada ainda é lucrativa no curto prazo" foram as questões mais valorizadas pelos especialistas consultados, alcançando $15,0 \%$ e 12,2\%, respectivamente. Destacaram-se, ainda, "o avanço da agricultura e da pecuária na Amazônia" e "a inexistência de políticas de regularização fundiária", com $11 \%$ e $10 \%$ do percentual total de respostas, respectivamente. Entretanto, os resultados sugerem que a "falta de políticas para o uso de terras" representa uma baixa ameaça ao manejo florestal na Amazônia (7,0\% do total das respostas).

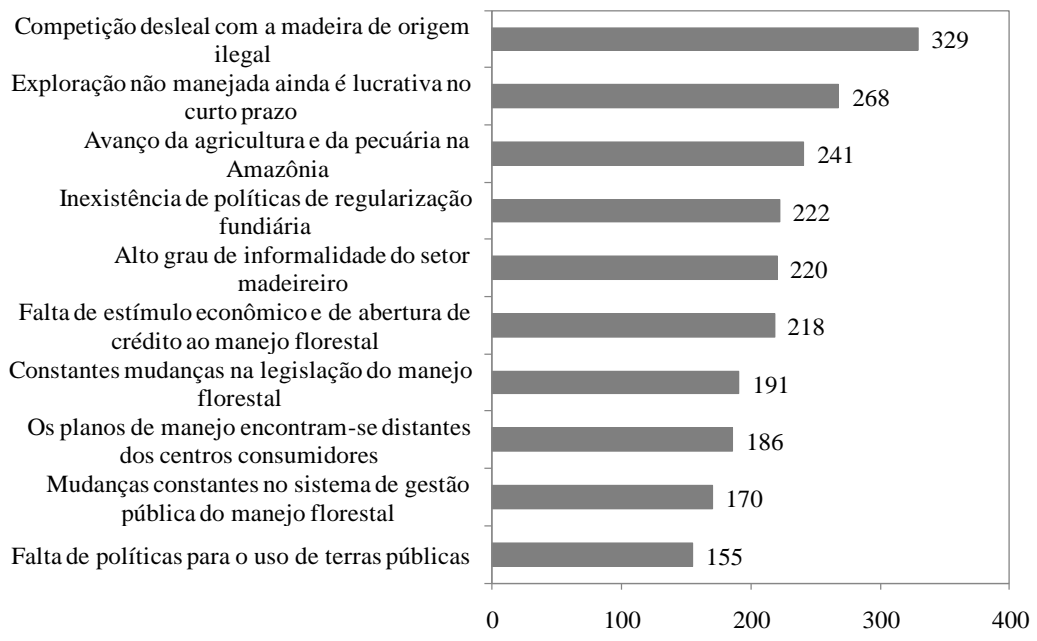

Figura 5. As ameaças do manejo florestal e pontuações segundo os grupos avaliados. Figure 5. The threat to forest management and scores according to the evaluated groups. 
As evidências apontadas na literatura reforçam a percepção dos diferentes segmentos para as principais ameaças ao manejo florestal na Amazônia (Figura 5). Sabogal et al. (2000), estudando as limitações e oportunidades do manejo florestal empresarial na Amazônia, argumenta que as ameaças estão ligadas, principalmente, à falta de políticas de regularização fundiária e ao alto grau de informalidade do setor madeireiro naquela região. Veríssimo (2005) afirma que a madeira retirada da floresta ilegalmente possui preços bastante reduzidos no mercado, se comparada com aquela produzida a partir de planos de manejo. Esse último aspecto inviabiliza os investimentos em manejo florestal, em razão do elevado custo da madeira.

Destaca-se que os valores atribuídos ao "avanço da agricultura e da pecuária na Amazônia" possivelmente foi influenciado pela aparente relação entre bons preços de commodites agrícolas, nos mercados nacional e internacional, com o aumento do desmatamento. Desse modo, quando os preços das commodities aumentam, a quantidade de áreas convertidas também aumenta.

Por último, cabe ressaltar que existe um inter-relacionamento entre as questões mais valorizadas, uma vez que representam ameaças inerentes à manutenção do recurso florestal na Amazônia. Primeiramente, a competição desleal, entre a madeira proveniente da exploração predatória e a madeira de manejo florestal, tem forte relação com o fato de que a extração de madeira predatória, ainda, é mais lucrativa, no curto prazo. Em segundo lugar, a inexistência de política fundiária para a Amazônia é fator de ameaça ao manejo, uma vez que as terras devolutas passam pelo processo da grilagem e são ocupadas de forma irregular.

\section{CONCLUSÕES}

- Os principais pontos fortes do manejo florestal na Amazônia devem-se à possibilidade de manutenção da cobertura florestal e à garantia da produção de madeira, sugerindo o manejo como uma boa alternativa de desenvolvimento sustentável em longo prazo sem a necessidade de mudança do uso da terra na área rural da Amazônia. Porém não foi destacado um grande potencial do manejo na Amazônia na geração de renda e emprego, sugerindo a necessidade do desenvolvimento de alternativas para atender esse fim, talvez o incentivo a indústrias com maior valor agregado comparativamente à indústria de base florestal.

- Outros pontos fortes relacionados a questões ambientais mais específicas, bem como ganhos de mercado devido a uma possível diferenciação da madeira manejada ou desenvolvimento do mercado de não madeireiros destacaram-se em uma posição intermediária e o fato de possuir áreas de MFS, aparentemente, não é um ponto forte perante os órgãos ambientais reguladores. Em geral, a percepção de atuação do governo como indutor ou facilitador ao manejo não foi bem vista pelos entrevistados.

- Os pontos fracos do manejo estiveram relacionados principalmente a aspectos de cunho governamental, tais como burocracia, falhas em fiscalização, problemas relacionados à falta de crédito compatível com a atividade e falta de infraestrutura, entre outros. As limitações técnicas do manejo de florestas naturais como, por exemplo, o longo ciclo das florestas, não foram relacionadas entre seus principais pontos fracos.

- As principais oportunidades em relação ao manejo florestal da Amazônia foram relacionadas ao desenvolvimento do mercado de madeiras tropicais e, com menos importância, ao crescimento dos mercados de produtos não madeireiros e de carbono. Provavelmente, questões como a escassez de madeira tropical nos principais países concorrentes, exemplo da Malásia e Indonésia, somada ao forte crescimento da China e a posição extremamente favorável da Amazônia quanto à distância ao maior consumidor de produtos florestais do mundo, os EUA, pesaram na opinião dos entrevistados.

- Bem distante das alternativas oferecidas, a principal ameaça ao desenvolvimento do manejo esteve relacionada à concorrência desleal com madeira de desmatamento, refletindo um pessimismo quanto à resolução desse problema em curto prazo, principalmente em função da expansão da agricultura e pecuária. Somado a esses, outros fatores referentes ao desenvolvimento de uma indústria madeireira forte, os quais possibilitariam o surgimento de uma indústria de base florestal concorrente à agricultura e com capacidade de aproveitar as vantagens da utilização da madeira manejada, também foram percebidas como uma considerável ameaça ao desenvolvimento do manejo florestal na Amazônia.

\section{REFERÊNCIAS}

ANGELO, H.; PRADO, A. C.; BRASIL, A. A. Influência do manejo florestal e do desmatamento na oferta de madeiras tropicais na Amazônia brasileira. Ciência Florestal, Santa Maria, v. 14, n. 2, p. 103 - 109, 2004. 
AGARWAL, R.; GRASSL, W.; AND PAHL, J. Meta-SWOT: introducing a new strategic planning tool. Journal of Business Strategy, Bingley, v. 33, n. 2, p. 12 - 21, 2012.

COMAN, A.; RONEN, B. Focused SWOT: diagnosing critical strengths and weaknesses. International Journal of Production Research, Abingdon, v. 47, n. 20, p. 32 - 43, 2009.

DA SILVA, J. C. Análise estratégica da produção madeireira sustentada na Amazônia brasileira. 117 f. Tese (Doutorado em Ciências Florestais) - Departamento de Engenharia Florestal da Universidade de Brasília, Brasília, 2005.

FREITAS, M. A ilusão da sustentabilidade. Manaus: Edições Governo do Estado do Amazonas/Secretaria de Estado de Cultura/Editora da Universidade do Estado do Amazonas: 2003. $324 \mathrm{p}$.

FINCO, M. V. A; RODRIGUES, W, RODRIGUES, I. A Amazônia legal brasileira e o mercado de créditos de carbono: perspectivas para o Estado do Tocantins. Amazônia: Ciência \& Desenvolvimento, Belém, v. 2, n. 3, p. 60 - 74, 2006.

HELMS, M. M.; NIXON, J. Exploring SWOT analysis - where are we now?: A review of academic research from the last decade. Journal of Strategy and Management, Reino Unido, v. 3, n. 3, p. 215 - 251, 2010.

HOMMA, A. K. O. Amazônia: como aproveitar os benefícios da destruição? Dossiê Amazônia brasileira II, São Paulo, v. 19, n. 54, 2005.

MARENGO, J. A. Mudanças climáticas globais e seus efeitos sobre a biodiversidade: caracterização do clima atual e definição das alterações climáticas para o território brasileiro ao longo do século XXI. Brasília: Ministério do Meio Ambiente (MMA), 2006. 201 p.

Matsunaga, A. T. Análise Econômica da Cadeia Produtiva da Madeira Oriunda de Plano de Manejo Florestal: Estudo de Caso. 115 f. Dissertação (Mestrado em Ciências Florestais) Departamento de Engenharia Florestal da Universidade de Brasília, Brasília, 2005.

NASRI, W. (2011). Competitive intelligence in Tunisian companies. Journal of Enterprise Information Management, Reino Unido, v. 24, n. 1, p. 53 - 67, 2011.

REMADE. Florestas canadenses - Um vasto e complexo recurso. Revista da Madeira, Curitiba, n. 66, 2002.

SABOGAL, C.; LENTINI, M.; POKORNY, B.; BERNARDO, P.; MASSIH, F.; SOBRAL, L. Amazônia sustentável: limitantes e oportunidades para o desenvolvimento rural. Brasília: Imazon e Banco Mundial; 2000. $77 \mathrm{p}$.

ULRICH, S. MAPA - Manual de Planejamento e Avaliação de Projetos. 1. ed. Cascais: Principia, 2002. $104 \mathrm{p}$.

VERÍSSIMO, A. Manejo Florestal Empresarial na Amazônia Brasileira: restrições e oportunidades para a adoção de boas práticas de manejo. Belém: Cifor-Imazon-EMBRAPA-FFT. 2005. 107 p. 